\title{
OPSICODRAMA PEDAGÓGICO: ESTRATÉGIA PARA A HUMANIZAÇÃO DAS RELAÇÕES DE TRABALHO
}

\author{
PEDAGOGICAL PSYCHODRAMA: A STRATEGY FOR THE HUMANIZATION OF WORK \\ RELATIONSHIPS
}
EL PSICODRAMA PEDAGÓGICO: ESTRATEGIA PARA HUMANIZAR LAS RELACIONES
DE TRABAJO

\author{
Toyoko Saeki ${ }^{1}$ \\ Adriana Kátia Corrêa ${ }^{2}$ \\ Maria Conceição Bernardo de Mello e Souza ${ }^{1}$ \\ Maria Lúcia Zanetti
}

RESUMO: Este estudo teve como objetivo analisar a utilização do psicodrama pedagógico como estratégia para refletir sobre a humanização do atendimento em saúde. Foram realizados cinco encontros, de maio a junho de 2000. As temáticas desenvolvidas foram: o contexto de trabalho em urgência e a atualização da referência pessoal e profissional, individual e grupal; reconhecimento do usuário. Tendo em vista a necessidade de se repensar a humanização do atendimento em emergência, consideramos que a abordagem psicodramática despertou o trabalhador para o compromisso e responsabilização com o trabalho.

PALAVRAS - CHAVE: enfermagem, psicodrama, serviço

ABSTRACT: The aim of this study is to analyze the use of pedagogical psychodrama as a strategy for reflecting on the humanization of health care. Five meetings were held from May to June 2000. In these meetings the following themes were developed: context of work in emergencies; updating of the personal and professional, individual and group reference, and acknowledgement of users. In view of the need of rethinking humanization in emergency care, we consider that the psychodrama approach alerted health professionals for the necessary commitment and responsibility in their work.

KEYWORDS: nursing, psychodrama, service

RESUMEN: Este estudio tuvo como objetivo analizar la utilización del psicodrama pedagógico como estrategia para reflexionar sobre la humanización del atendimiento en salud. Fueron realizados cinco encuentros, de mayo a junio de 2000. Las temáticas desarrolladas fueron: el contexto de trabajo en urgencia y la actualización de la referencia personal y profesional, individual y grupal; reconocimiento del usuario. Llevando en cuenta la necesidad de repensar la humanización del atendimiento en emergencia, consideramos que la propuesta psicodramática le hizo despertar al trabajador el compromiso y la responsabilidad hacia su trabajo.

PALABRAS CLAVE: enfermeria, psicodrama, trabajo

Recebido em 12/09/2001

Aprovado em 18/12/2001

\footnotetext{
${ }^{1}$ Professor Doutor do Departamento de Enfermagem Psiquiátrica e Ciências Humanas - Escola de Enfermagem de Ribeirão Preto da Universidade de São Paulo.

2 Professor Doutor do Departamento de Enfermagem Geral e Especializada da Escola de Enfermagem de Ribeirão Preto da Universidade de São Paulo.
} 


\section{INTRODUÇÃO}

Considerando as propostas de mudanças organizacionais de um hospital de emergência de grande porte, no interior do estado de São Paulo, elaboramos um programa educativo contemplando aspectos inerentes à humanização das relações interpessoais no ambiente de trabalho. Essas mudanças estão relacionadas com a proposta de constituição de um modelo de gestão participativo em substituição ao tradicional até então vigente. O modelo de gestão participativo envolve a formação de unidades gestoras de trabalho, com a participação de vários profissionais, sendo a proposta básica constituir uma gestão interdisciplinar, participativa e flexivel que ofereça condições para a recriação das práticas cotidianas, com ênfase no desenvolvimento do compromisso, envolvimento e competência do trabalhador, com o intuito de qualificar o atendimento ao usuário. Nesse processo de transformação organizacional, a relação dos profissionais com os usuários pôde ser repensada. Um dos pontos que se mostrou crítico foi o atendimento de recepção de urgência, no que se refere à necessidade de humanizar as relações interpessoais, foco do programa educativo proposto.

O referencial teórico que fundamentou a elaboração da proposta educativa foi o psicodramático, considerando que possibilita aos participantes refletirem, de forma espontânea e criativa, sobre suas vivências no cotidiano de trabalho.

O psicodrama pode ser utilizado tanto como recurso psicoterápico como pedagógico. Neste estudo, utilizamos o psicodrama pedagógico que envolve aprendizagem diferente da tradicional. Enfatiza o trabalho em grupo através da ação, resgata o sentido lúdico e pedagógico da comunicação, facilitando a expressão e o entendimento das idéias. Desse modo, propicia a exteriorização de problemas e dificuldades imaginadas, permitindo sua exploração e entendimento vivencial (MÜHLEMBERG, 1999).

Assim, o objetivo deste estudo foi analisar a utilização do psicodrama como estratégia pedagógica para refletir sobre a humanização do atendimento em saúde, especificamente, em um serviço de emergência.

\section{TRAJETÓRIA METODOLÓGICA}

Estudo descritivo (TRIVINÕS, 1992), realizado em uma Unidade de Emergência de um Hospital Escola do interior do Estado de São Paulo. Foi implementado um programa educativo com a supervisão de uma psicodramatista, no periodo de 16 de maio a 17 de junho de 2000 , totalizando cinco encontros, com carga horária de 15 horas. Participaram 24 funcionários dos serviços de portaria, registro, escolta, ascensorista e do serviço social, subdivididos em dois grupos.

As temáticas desenvolvidas foram: o contexto de trabalho em urgência e a atualização da referência pessoal e profissional, individual e grupal; o reconhecimento do usuário da unidade de emergência - resgate do senso de realidade e de percepções objetiva e humana do outro; formas de relacionamentos e responsabilização que favoreçam a capacidade de dar respostas éticas e de respeito à cidadania dos usuários.

As etapas utilizadas para o desenvolvimento das temáticas, em cada encontro, foram: o aquecimento inespecifico, o aquecimento especifico, a ação e os comentários finais. No aquecimento inespecifico foram propostas algumas atividades como relaxamento, expressão corporal, dança e jogos de forma a preparar os participantes para os momentos subseqüentes. No aquecimento especifico, os participantes foram sensibilizados para a temática proposta em cada encontro, como por exemplo, que pensassem em situações vivenciadas no trabalho, nas relações com os colegas, nas facilidades e dificuldades encontradas para o desenvolvimento de suas atividades, dentre outros.

Em seguida, no desenvolvimento da ação, os funcionários retomavam os pensamentos e os sentimentos experimentados no aquecimento especifico, expressando-os através de movimentos corporais, cenas e desenhos. No final, solicitávamos que os participantes comentassem sobre a atividade desenvolvida, sendo feita relação com o trabalho cotidiano.

No desenvolvimento de cada etapa, era enfocada a relação "eu - comigo; eu - com - o - outro e eu - com - todos" fundamental no psicodrama pedagógico. Após cada encontro, os coordenadores se reuniam para discutir a vivência e registravam o que emergiu no grupo e também as suas observações e percepções. Posteriormente, era realizada a supervisão com a psicodramatista, com o intuito de avaliar e planejar o próximo encontro.

\section{IMPLEMENTAÇÃO DA PROPOSTA PEDAGÓGICA}

A utilização do psicodrama como estratégia pedagógica possibilitou aos participantes refletirem sobre si mesmos, sua inserção no local de trabalho e suas relações com os demais trabalhadores e usuários. As etapas desenvolvidas no processo educativo despertaram a espontaneidade e a 
criatividade ${ }^{3}$ do trabalhador, facilitando a expressão de pensamentos e sentimentos sobre suas vivências no cotidiano.

Isso foi possivel pois, o psicodrama pedagógico propõe uma aprendizagem diferente da tradicional, privilegiando a vivência que envolve o pensar, o sentir e o agir, produzindo resultados que podem permanecer com os participantes por longo tempo (DATNER, 1999).

Nos encontros realizados, emergiram algumas questões referentes às relações no trabalho e significativas para repensar a humanização no contexto da emergência:

O grupo, de modo geral, demonstrou uma baixa auto-estima em relação ao seu trabalho, o que parece ser gerado pela falta de informações, de espaços para opinar, de reconhecimento e valorização de suas atividades pelos colegas e chefias; dificuldade de alguns funcionários em se perceberem como agentes responsáveis pela Unidade de Emergência. Frente aos problemas, depositam as responsabilidades em outros ou na "Instituição" (como se ela existisse à parte de si mesmos), posicionando-se de modo pouco envolvido com as situações cotidianas; alguns funcionários vêem a instituição de uma forma idealizada, apresentando dificuldade para analisar o seu fazer, enquanto alguns outros mostram vontade em imprimir sua marca no trabalho; observam-se problemas na comunicação entre os funcionários, funcionários e chefia e entre os diversos setores, como a falta de repasse e fragmentação de informações; alguns servidores mostraram-se presos a regras e normas e sem preparo ético e humano suficiente para lidar com os usuários da Unidade de Emergência, o que se traduz em atitudes, às vezes, pouco flexiveis e até de desrespeito. Essa situação revela a instituição engessada em regras e papéis a cumprir. Os participantes, em muitos momentos, relataram que o seu trabalho cotidiano mobiliza sentimentos, preocupações e ansiedades e que não encontram espaços adequados para serem elaborados.

Nesta direção, na saúde, necessário se faz reaproximar os funcionários do resultado de seu trabalho, resgatando a valorização do orgulho profissional pelo esforço singular realizado, de forma que eles possam se reconhecer, ser valorizados e ter respeito público (CAMPOS, 1997).

\section{CONSIDERAÇÕES FINAIS}

A partir da nossa vivência e da avaliação realizada pelos participantes ao final do curso, compreendemos que o programa desenvolvido possibilitou aos funcionários a reflexão sobre seu cotidiano de trabalho, envolvendo as suas relações com os usuários, demais funcionários e chefias. Consideramos que a abordagem do psicodrama despertou o trabalhador para o compromisso, criação de vinculos e responsabilização com o trabalho, atitudes necessárias para repensar a humanização do atendimento em emergência. Nesse sentido, ressaltamos a importância de implementar estratégias administrativas e pedagógicas para que o processo por eles vivenciado tenha continuidade e ressonância.

\section{REFERÊNCIAS BIBLIOGRÁFICAS}

CAMPOS, G.W.S. Subjetividade e administração de pessoal: considerações sobre modos de gerenciar o trabalho em equipe de saúde. In: MERHY, E.E.; ONOCKO, R. Agir em saúde - um desafio para o público. São Paulo: Hucitec, 1997. Cap.7, p.229-266.

DATNER, Y.B. O psicodrama para a educação no trabalho: uma proposta. Linhas Críticas, Brasilia, n.7-8, v.4, p.7986, 1999.

GONÇALVES, C.S.; WOLFF, J.R.; ALMEIDA, W.C. Lições de psicodrama: introdução ao pensamento de J.L.Moreno. 5.ed. São Paulo: Ágora, 1998.

MORENO, J.L. Psicodrama. 10. ed. São Paulo: Cutrix,1993.

MÜHLEMBERG, L.M. Mobilização social e psicodrama no trabalho comunitário. Linhas Críticas, Brasília, n.4, v.7/8, p.99-102, 1999.

TRIVINÕS, A.N.S. Introdução à pesquisa em ciências sociais. São Paulo: Atlas, 1992.

\footnotetext{
${ }^{3}$ A espontaneidade é a resposta do individuo a uma nova situação e a nova resposta a uma antiga situação (MORENO, 1993). A criatividade é indissociável da espontaneidade. A espontaneidade é um fator que permite ao potencial criativo atualizar-se e manifestar-se (GONÇALVES; WOLFF; ALMEIDA, 1998, p.47).
} 